\title{
원조 투명성 및 효과성 제고와 IATI 가입
}

제I장

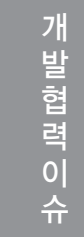

제II장

제III장

제IV장

1. 아크라 세계개발원조총회와 IATI 출범

2. IATI 개관

1) IATI의 비전 및 정보공개 기준

2) IATI의 구성 및 활동

III.우리나라의 IATI 가입

1. IATI 가입의 기대 성과

2. 현황 및 향후 계획

IV.결론

\section{I. 서론}

해방 이후 1990 년대 후반까지 한국은 수원국으로서 국제사회로부터 약 120 억 달러의 공적원조 를 받았다. 한국은 이러한 대외 원조 및 국내재원을 활용하여 짧은 기간에 비약적으로 성장하였고, 이에 따라 1995년 세계은행의 차관 졸업국 지위를 획득하고, 2000년에는 경제협력개발기구 개발원 조위원회(OECD DAC) 수원국 리스트에서 제외되었다. 이어 2010년 OECD DAC에 가입함으로써 한 국은 전후 최빈 수원국에서 공여국으로 전환한 개발 성공국으로서 국제사회의 높은 관심을 받게 되 었다. 한편, 한국의 대외 원조 규모도 지속 증가하여 ODA 지원규모는 1993년 1.1억 달러에서 2013 년 17.5억 달러로 지난 20 년간 약 16 배의 증가를 달성하였다. 
〈표 1〉한국의 ODA 지원실적

\begin{tabular}{c|c|c|c|c|c|c|c|c|c|c}
\hline 양/다자 & 1993 & 2005 & 2006 & 2007 & 2008 & 2009 & 2010 & 2011 & 2012 & 2013 \\
\hline 합계 & 111.56 & 752.32 & 455.25 & 696.11 & 802.34 & 816.04 & $1,173.72$ & $1,324.59$ & $1,597.45$ & $1,755.38$ \\
\hline $\begin{array}{c}\text { 양자간 } \\
\text { ODA }\end{array}$ & 60.12 & 463.30 & 376.06 & 490.52 & 539.22 & 581.10 & 900.56 & 989.57 & $1,183.17$ & $1,309.58$ \\
\hline $\begin{array}{c}\text { 다자간 } \\
\text { ODA }\end{array}$ & 51.44 & 289.01 & 79.19 & 205.59 & 263.12 & 234.94 & 273.15 & 335.02 & 414.28 & 445.80 \\
\hline
\end{tabular}

(순지출기준, 백만불)

* 출처 : 한국수출입은행 $\mathrm{DB}$

\section{〈그림 1〉한국의 ODA 지원 실적}

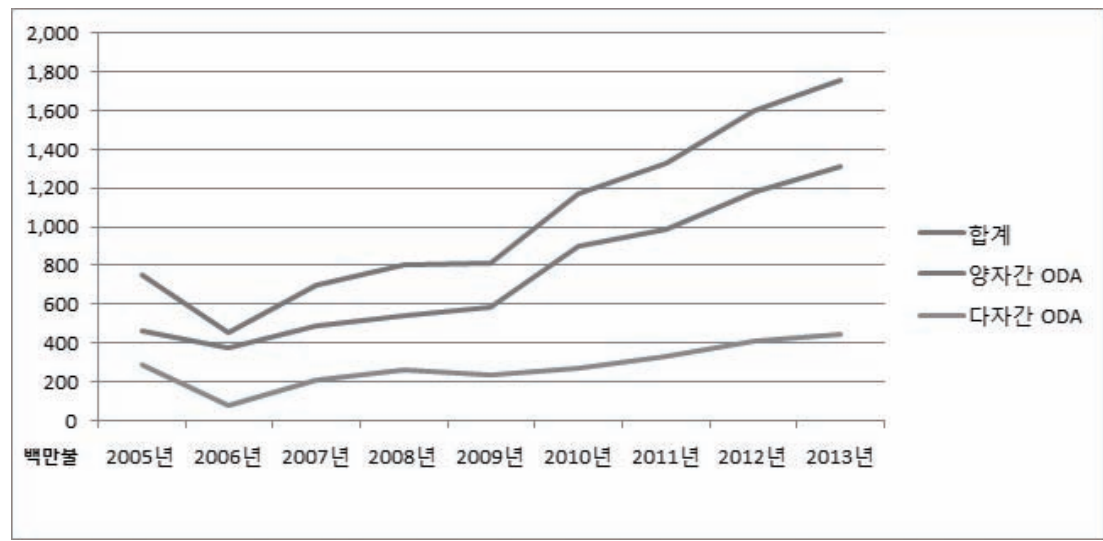

* 출처 : 한국수출입은행 $\mathrm{DB}$

이러한 $\mathrm{ODA}$ 규모의 확대에 따라 국내적으로는 국회, 시민사회, 학계 등으로부터 ODA 예산 집 행의 투명성 제고에 대한 요구가 증가해 왔다. 이와 더불어, $\mathrm{OECD}, \mathrm{UN}$ 등 국제사회에서는 원조 의 절대적인 규모를 증가시키는 것도 중요하지만, 제공된 원조가 효과적으로 개도국의 개발에 활용 될 수 있도록 하기 위해서는 원조의 투명성을 증가시키는 것이 필수적이라는 공감대가 형성되었다. 공여국의 투명한 원조 정보 공개로 수원국의 원조 예측성이 높아지면 수원국이 주인의식(national ownership)을 가지고 개발 노력을 기울이게 되어 원조 효과성이 제고될 수 있기 때문이다.

"투명성은 특히 개발효과성 제고를 위해 우리나라에 중요하다. 투명성의 증가는 정부의 책무성을 제고 하고, 결과적으로 국가의 주인의식 및 개발 결과를 강화한다(네팔, 2013 IATI Annual Report)."

"원조 흐름의 투명성은 정부가 대내외 모든 재원을 국가의 우선순위에 따라 계획하고, 예산 편성하고, 배분할 수 있도록 촉진할 것이다(르완다, 2014 IATI Annual Report)." 
중진 공여국으로서 우리 개발협력 정책의 선진화를 위해 노력하고 있는 한국은 원조의 효과성 제 고를 위해서는 원조의 투명성 확보가 필수적이라는 기조 하에 우리 원조 투명성 제고를 위해 국제원 조투명성기구(International Aid Transparency Initiative, IATI) 가입을 추진 중이다. 본고에서는 IATI의 출범 및 활동을 중심으로 IATI에 대해 살펴본 후 우리 정부의 IATI 가입 결정 및 관련 준비 내용을 소개한다.

제I장

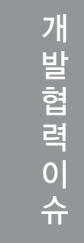

제II장

\section{1. 아크라 세계개발원조총회와 IATI 출범}

2008년 9월 아크라에서 개최된 제3차 세계개발원조총회(the Third High Level Forum on Aid Effectiveness (HLF-3))는 결과문서인 아크라 행동계획(Accra Agenda for Action)을 채택하였다. 이 행동계획 상의 투명성 관련 공약 이행 지원을 위해 주요 공여국 및 국제기구 등은 원조 투명성 제 고를 위한 자발적인 활동을 추진키로 하고, 자발적 - 다주체(multi-stakeholder) 이니셔티브로서 2009년 IATI가 출범하였다.

\section{아크라 행동계획(Accra Agenda for Action)}

책무성 및 투명성 제고(We will be more accountable and transparent to our publics for results)

24. 투명성 및 책무성은 개발 결과를 위해 필수적인 요소이다. 이는 파리 선언의 중심인데, 파리 선언에 서 우리는 국가들 및 공여국들이 서로와 국민들에게 더욱 책임감을 느끼도록 한다는데 동의하였다. 우리는 다음의 행동을 취함으로써 이런 노력을 추구한다.

a) 우리는 보다 투명한 원조를 시행한다. 개도국은 수입, 예산, 지출, 정부조달, 감사의 대중 공개를 포함한 공공 금융관리의 투명성을 통해 의회의 감독을 촉진한다. 공여국은 개도국의 보다 정확 한 예산, 회계 및 감사를 위해, 개발협력 관련 전체 지출 규모, 배분 및 결과에 관한 정보의 정기 적이고 상세하며, 시의적절한 공개를 시행한다.(후략)

공여조건의 본질 전환 (We will continue to change the nature of conditionality to support ownership)

25. 국가 주인의식 강화 및 원조흐름의 예측성 제고를 위해, 공여국은 개도국 자체의 개발정책에서 조 건들을 끌어낼 것이라고 파리선언에서 합의하였다. 우리는 이 원칙에 대한 공약을 재확인하고, 다음 의 행동을 취함으로써 공여조건의 본질을 바꿀 것이다. (중략)

b) 지금부터, 공여국 및 개도국은 원조재원 집행과 관련된 모든 조건을 공개한다.

24. Transparency and accountability are essential elements for development results. They lie at the heart of the Paris Declaration, in which we agreed that countries and donors would become more accountable to each other and to their citizens. We will pursue these efforts by taking the following actions: 
a) We will make aid more transparent. Developing countries will facilitate parliamentary oversight by implementing greater transparency in public financial management, including public disclosure of revenues, budgets, expenditures, procurement and audits. Donors will publicly disclose regular, detailed and timely information on volume, allocation and, when available, results of development expenditure to enable more accurate budget, accounting and audit by developing countries.

25. To strengthen country ownership and improve the predictability of aid flows, donors agreed in the Paris Declaration that, whenever possible, they would draw their conditions from developing countries' own development policies. We reaffirm our commitment to this principle and will continue to change the nature of conditionality by taking the following actions:

b) Beginning now, donors and developing countries will regularly make public all conditions linked to disbursements.

아크라 세계개발원조총회(Third High Level Forum On Aid Effectiveness, 2008. 9. 2-4)

\section{IATI 개관}

\section{1) IATI의 비전 및 정보공개 기준}

IATI는 개발 협력과 인도주의적 원조 제공 과정에서 모든 참여자들에 의한 모든 활동을 적절한 시기에 투명하고, 포괄적으로 보고하는 공통의 전자적 포맷(electronic format)을 구성하는 것을 비 전 ${ }^{1)}$ 으로 삼고 있다.

현재 매년 OECD DAC 국가들은 CRS++(Creditor Reporting System)를 의무적으로 보고하고 있다. $\mathrm{CRS}++$ 는 공여국 및 기관의 책임성에 초점을 두고, $\mathrm{ODA}$ 자원에 한정하여 검증된 과거의 실 적자료 제공을 요구한다. 이와는 다르게 IATI는 개도국의 정보수집 수요에 근거하여 ODA를 포함한 모든 자원에 대한 정보를 포함하며 예측 가능한 미래의 지원규모 정보를 제공하는데 중점을 두고 있 다. 이렇게 $\mathrm{CRS}++$ 와 IATI 데이터는 많은 측면에서 서로 다른 시스템이나 원조 정보 공개를 통한 투명성 제고를 위해 보완적인 역할을 수행한다고 볼 수 있다.

\section{2) IATI의 구성 및 활동}

IATI는 운영위원회(Steering Committee), 사무국(Secretariat), 기술자문그룹(Technical

1) A common electronic format for the transparent, timely and comprehensive reporting of all activities by all participants in the delivery of development cooperation and humanitarian aid 
Advisory Group)을 통해 운영되고 있다. 운영위원회는 IAIT의 회원들로 구성되며, 연간 2차례 회 의를 개최하여 IATI의 정책 및 전략방향 등을 결정한다. 사무국은 정보공개 기준 수립 및 IATI 이행 촉진을 위한 지원 역할을 수행하며, 다양한 회원국 및 기관 구성을 반영하여 UN 개발계획(United Nations Development Programme, UNDP), UN 연구사업소(United Nations Office for Project Services, UNOPS), 스웨덴, 가나, Development Initiatives의 컨소시엄 형태로 운영되고 있다. $\mathrm{UNDP}$ 는 사무국을 총괄하고, UNOPS는 재정, 행정사항 및 보고를 담당한다. 스웨덴과 가나는 각각 공여국, 수원국에 대한 아웃리치를 담당하며, Development Initiatives는 기술지원 및 CSOs와 신흥 공여국에 대한 아웃리치를 담당하고 있다. 한편, 기술자문그룹은 참여국 및 기관의 IATI 이행을 지 원하고, 개도국에서의 IATI 시범사업을 수행한다.

IATI의 회원은 IATI의 목적, 공약에 동의하는 공여국, 국제기구, 수원국, NGOs 등을 망라하며, 회원이 되기 위해서는 IATI 아크라 선언(Accra Statement)에 서명하고 이행체제(Framework for Implementation)를 승인하여야 한다. 2014년 현재 정회원(fee-paying member)은 59개, 정회원 포함 정보공개 참여국/기관은 210개에 이른다(2014 IATI Annual Report). IATI에 가입한 공여국 은 호주, 벨기에, 캐나다, 덴마크, 핀란드, 독일, 미국, 네덜란드, 뉴질랜드, 노르웨이, 스페인, 스웨 덴, 스위스, 영국, 아일랜드 등의 15 개국이다.

IATI는 ODA 관련 공통의 정보 공개 기준을 마련하여, 회원이 자발적으로 ODA 지원실적, 향후 지원계획, 국별지원전략 등 관련 정보를 분기별로 제공토록 지원하며, 회원은 IATI의 정보 공개 양 식에 맞춰 자체 웹사이트에 해당 정보를 공개하고 IATI 웹사이트에도 이를 등록하게 된다(〈표 2〉참 고). 
〈표 2〉|ATI 회원의 정보공개 현황

\begin{tabular}{|c|c|c|}
\hline 회원 & 가입 & 정보공개 \\
\hline Adaptation Fund & 2013년 4월 & - \\
\hline 아프리카 개발은행(ADB) & 2011년 4월 & 2013년 6월 \\
\hline 호주(외교통상부) & 2008년 9월 & 2011년 9월 \\
\hline 벨기에 & 2012년 11월 & - \\
\hline 빌앤멜린다게이츠 재단(BMGF) & 2013년 10월 & - \\
\hline Bond & 2013년 11월 & 2012년 7월 \\
\hline 캐나다(외교통상개발부) & 2011년 11월 & 2012년 10월 \\
\hline 덴마크(Danida, 외교부) & 2008년 9월 & 2012년 3월 \\
\hline Development Initiatives Poverty Research & 2008년 11월 & 2011년 7월 \\
\hline EC & 2013년 10월 & - \\
\hline 유럽투자은행(EIB) & 2013년 10월 & - \\
\hline 핀란드(외교부) & 2008년 9월 & 2011년 11월 \\
\hline 독일(경제협력개발부) & 2008년 9월 & 2013년 3월 \\
\hline 지구환경금융(GEF) & 2013년 3월 & - \\
\hline Inter-American Development Bank & 2011년 11월 & 2013년 3월 \\
\hline 국제농업개발기금(IFAD) & 2012년 5월 & - \\
\hline 아일랜드(Irish Aid, 외교통상부) & 2008년 9월 & 2013년 7월 \\
\hline 네덜란드(외교부) & 2008년 9월 & 2011년 9월 \\
\hline 뉴질랜드(외교통상부) & 2008년 9월 & 2012년 5월 \\
\hline 노르웨이(NORAD, 외교부) & 2008년 9월 & - \\
\hline Publish What You Fund & 2008년 11월 & 2011년 11월 \\
\hline 스웨덴(SIDA) & 2008년 9월 & 2011년 10월 \\
\hline 스위스(SDC) & 2009년 6월 & 2013년 11월 \\
\hline 에이즈, 결핵, 말라리아 퇴치 글로벌 기금 & 2011년 6월 & 2011년 11월 \\
\hline The William and Flora Hewlett Foundation & 2008년 9월 & 2011년 3월 \\
\hline 세계은행 & 2008년 9월 & 2011년 5월 \\
\hline Transparency International Secretariat & 2008년 11월 & 2012년 5월 \\
\hline 영국(DFID) & 2008년 9월 & 2011년 1월 \\
\hline 유엔자본개발기금(UNCDF) & 2011년 12월 & 2012년 10월 \\
\hline 유엔아동기금(UNICEF) & 2012년 3월 & 2013년 6월 \\
\hline 유엔개발계획(UNDP) & 2008년 9월 & 2011년 11월 \\
\hline 유엔연구사업소(UNOPS) & 2011년 10월 & 2011년 10월 \\
\hline 유엔인도지원조정국(OCHA) & 2012년 8월 & - \\
\hline 유엔인구기금(UNFPA) & 2012년 5월 & 2013년 7월 \\
\hline 유엔여성기구(UN Women) & 2012년 5월 & 2012년 11월 \\
\hline 유엔세계식량계획(WFP) & 2012년 8월 & 2013년 6월 \\
\hline 미국 & 2011년 11월 & 2012년 12월 \\
\hline
\end{tabular}

* 출처: 2014 IATI Annual Report 


\section{III. 우리나라의 IATI 가입}

\section{IATI 가입의 기대 성과}

국내외 원조 투명성 제고 요청에 부응하기 위해 정부는 2014년 3월 국무총리 주재 하 개최된 제 18 차 국제개발협력위원회에서 우리 정부의 IATI 가입을 의결하였다. 이후 범정부적 의견 수렴을 거 쳐 현재 2016년 상반기 IATI 가입 및 원조정보 공개를 추진 중이다.

IATI에 가입함으로써 우리 개발협력 추진에 있어 여러 성과가 기대된다. 우선 투명한 원조 사업

\section{효과적인 개발협력을 위한 부산파트너십}

(Busan Partnership For Effective Development Co-Operation)

\section{투명하고 책임있는 협력(Transparent and responsible co-operation)}

23. 우리는 우리의 이 분야에서의 각자의 공약에 기반하여 개발협력 및 다른 개발원천에 관한 정보의 이용가능성 및 대중접근성 제고를 위해 노력한다. 이를 위해, (중략)

c) 개발협력을 통해 제공되는 재원들에 대한 시의적절하고 포괄적이며 미래 지향적인 정보의 전자 적 공개를 위해 공통의 공개된 기준을 이행한다. 동 기준은 OECD-DAC 통계 보고 및 국제원조 투명성기구와 다른 보완적인 보고 체계를 고려하여 추진한다.

23. We will work to improve the availability and public accessibility of information on development cooperation and other development resources, building on our respective commitments in this area. To this end, we will:

c) Implement a common, open standard for electronic publication of timely, comprehensive and forward-looking information on resources provided through development cooperation, taking into account the statistical reporting of the OECD-DAC and the complementary efforts of the International Aid Transparency Initiative and others.

부산 세계개발원조총회(Fourth High Level Forum On Aid Effectiveness, 2011. 11. 29 - 12. 1)

2) 국무조정실, 외교부, 기획재정부는 한국의 개발협력에 관한 포괄적인 정보를 제공함으로써 투명성과 책무성을 지 속적으로 높여야 한다. 특히, 이들은 중요한 행위자들(의회, 시민사회단체, 비정부기구, 민간부문, 연구기관, 개도 국 파트너 및 일반 대중들)의 접근 및 이해가 용이한 방식으로 개발협력 정책, 전략, 절차, 예산, 프로그램 및 프 로젝트에 관한 정보를 제공해야 한다. (PMO, MOFAT, and MOSF should continue to increase transparency and accountability by providing comprehensive information on Korea' $s$ development cooperation - in particular, they should disclose information on development cooperation policy, strategy, procedures, budget(countries and sectors), programmes and projects in a way that is easy for key stakeholders - parliamentarians, civil society organizations (CSOS), non-government organizations(NGOs), private sector, research institutes, developing country partners and the general public - to access and understand.)

3) 현재 국제적인 공통 기준은 OECD/DAC CRS, FSS(Forward Spending Survey) 및 IATI의 세 가지 보완적인 시스템 으로 구성된다. 
수행이 가능해져 우리 원조의 질적 향상 및 원조 예산의 효율적 집행을 도모할 수 있다. 둘째, 원조 관련 정보 공개를 통해 전반적인 원조 수행 과정에 대한 국민들의 관심과 지원을 확보할 수 있다. 원 조에 필요한 재원은 국민들의 세금으로 이루어짐을 감안할 때, 세금 납부자의 적절한 관심과 지지 는 원조 정책의 성공을 위해 필수적이다. 셋째, 2012년 우리나라가 처음으로 수검받은 $\mathrm{OECD} \mathrm{DAC}$ Peer Review시 제시된 정보제공 권고 ${ }^{2}$ 를 이행하는 효과가 있다. 동 Peer Review에서는 우리 정부 에게 $\mathrm{ODA}$ 에 대한 종합적인 정보(정책, 전략, 예산, 사업 등)를 국민에게 제공하라는 권고를 내린 바 있는데, IATI 가입이 동 권고의 이행을 위한 하나의 방안이 될 수 있다. 마지막으로, 2011년 11월 개최된 부산 세계개발원조총회(the Fourth High Level Forum on Aid Effectiveness (HLF-4))의 공약을 이행하는 효과가 있다. 동 총회에서는 원조 정보 제공에 대한 국제적인 공통 기준(common standard $)^{3)}$ 이행시 IATI의 역할을 고려하라는 공약이 채택되었고, 우리 정부는 IATI 가입으로 동 공약을 이행하게 된다.

\section{2. 현황 및 향후 계획}

윤병세 외교장관은 2014년 멕시코에서 개최된 부산 글로벌파트너십 제 1 차 장관급회의에서 우리 정부의 IATI 가입 계획을 발표하였다. 이후 우리 정부는 여러 방면에서 IATI 가입 및 원조 정보 공개 관련 준비 작업을 진행 중이다.

제18차 국제개발협력위원회 의결에 따라 KOICA와 수출입은행이 2014년 상 - 하반기 두 차례 개 최된 IATI 운영위원회 회의에 옵서버로 참석하였고, IATI 가입준비 지원을 위한 데이터 산출 여건 등 준비현황 파악 및 기술 자문을 위해 IATI 기술자문그룹(Technical Advisory Group) 담당자를 초청하여 관계부처 및 기관과 의견을 나누는 기회를 가졌다. 한편, 국무조정실, 외교부, 기획재정부, $\mathrm{KOICA}$, 수출입은행으로 이루어진 '원조정보 공개 및 IATI 가입 $\mathrm{T} / \mathrm{F}$ ' 가 구성(2014.6월)되어 구체 적인 정보공개의 범위 및 시기 등을 포함한 로드맵을 작성하고 있다. 아울러, 외교부는 무상원조 시 행기관들과의 IATI 가입 관련 정보 공유 및 정보공개 참여 기관 범위 확대 논의를 위해 IATI 관련 무 상원조관계기관들과의 실무 협의를 개최하였고, $\mathrm{KOICA}$ 와 수출입은행은 원조정보 시스템 개선 및 관련 예산 확충 방안을 모색하는 등 범정부적인 노력이 진행 중이다.

이를 바탕으로 2015년 9월 뉴욕에서 개최될 Post-2015 정상회의에서 우리 정부의 IATI 가입 계 획을 발표하고, 제2차「국제개발협력 기본계획(2016-2020)」에 IATI 가입 이후 우리 ODA 투명성 제고를 위한 구체 계획을 반영할 예정이다. 


\section{IV. 결론}

원조의 투명성의 제고는 공여국의 원조예산 집행의 효율화 및 원조정책의 선진화에 도움이 될 뿐 아니라, 개발 현장에서 수원국의 원조 예측성을 높임으로써 효과적인 개발협력을 가능케 한다. 더 많은 원조와 동시에 더 효과적인 원조를 고민해야 하는 현재 각국이 원조 정책의 투명성을 확보하는 것은 피할 수 없는 선택이다. 한국은 비록 원조의 역사가 상대적으로 짧으나 개발에 성공한 경험을 기반으로 많은 개도국에게 영감을 제공하고 있다. 더 나아가 한국이 투명성 제고 등 개발협력 정책 의 선진화를 위해 끊임없이 노력하는 것은 다른 공여국에게도 귀감이 될 수 있을 것이다.

새로운 목표를 달성하기 위해 관련 제도를 정비하고 시스템을 구축해 나가는 일련의 활동은 많은 인내와 구성원들의 높은 지지를 필요로 한다. 원조 투명성 제고를 위해 결정한 IATI 가입도 그 준비 및 시행 과정에서의 어려움을 극복하기 위해서는 국민들의 관심과 지지가 필수적이다. 우리 정부의 원조 투명성 제고를 위한 새롭고 용기 있는 결정에 많은 국민의 지지를 요청한다. 


\section{〈참고문헌〉}

\section{1. 국외문헌}

OECD. 2012. Korea Development Assistance Committee(DAC) Peer Review 2012.

Paris. OECD. Retrieved from http://www. oecd.org/dac/peer-reviews/ Korea\%20CRC\%20-\%20FINAL\%2021\%20JAN.pdf

International Aid Transparency Initiative (IATI). 2013. “2013 IATI Annual Report”. Retrieved from http://www.aidtransparency.net/annual-report

. 2014. “2014 IATI Annual Report”. Retrieved from http://www. aidtransparency.net/annual-report

World Bank. 2008. “Accra Agenda for Action”. Washington D.C.: World Bank. Retrieved from http://siteresources.worldbank.org/ACCRAEXT/ Resources/4700790-1217425866038/AAA-4-SEPTEMBER-FINAL-16h00. pdf

4th High Level Forum on Aid Effectiveness. 2008. "Busan Partnership for Effective Development Cooperation". Retrieved from http://www.oecd.org/develo pment/effectiveness/49650173.pdf

\section{2. 참고 웹사이트}

ODA Korea, www.odakorea.go.kr

한국수출입은행, www. koreaexim.go. kr 